\title{
Artigos
}

Ariosto Sparemberger ${ }^{1}$

Cristian Sparemberger ${ }^{2}$

\section{UMA "RELEITURA" DA CIÊNCIA POLÍTICA DE NICOLAU MAQUIAVEL}

\section{A "REVIEW" OF NICOLAU MAQUIAVEL'S POLITICAL SCIENCE}

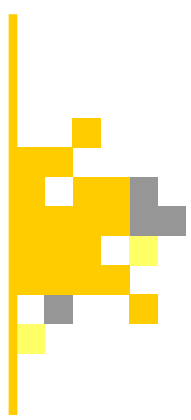

\section{RESUMO:}

Nicolau Maquiavel desenvolveu suas ideias no século XVI, no entanto, seus escritos e fama permanecem vivos ainda hoje. Porém, quem foi Nicolau Maquiavel? Quais ensinamentos políticos deixou? Por quais razões carrega demasiada fama? Qual a contribuição de Maquiavel à ciência política? Objetivando responder estas perguntas, o presente estudo, por meio do método de revisão bibliográfica, estabelece uma "releitura" - a partir de 3 visões distintas do pensamento político de Maquiavel -, retratando sua vida e os principais pontos presentes em suas obras, tais como o método utilizado por Maquiavel, os conceitos de virtù e fortuna e a relação de Maquiavel com a ética e a moral na política. Este trabalho apresenta de forma introdutória o pensamento de Maquiavel, vislumbrando servir como caminho de entrada aos que desejam mergulhar na ciência política maquiaveliana.

Palavras-chave: ciência política, ética, fortuna, Maquiavel, virtù.

\section{ABSTRACT:}

Machiavelli developed his ideas in the 16th century, however his writings and fame remain alive today, and consequently his name originated terms such as Machiavellianism and Machiavellian. However, for what reasons does this author carry too much fame? What political philosophies did Machiavelli teach? What is his contribution to political science? In order to answer these questions, the present study, using the bibliographic review method, establishes a "re-reading" - considering 3 different views of Machiavelli's political thought -, elucidating the main points present in the author's thought, such as the method used by Machiavelli, the concepts of virtù and fortune and Machiavelli's relationship with ethics. This work introduces Machiavelli's thought in an introductory way, aiming to serve as an entry for those who wish to dive into Machiavelli's political science.

Keywords: ethics, fortune, Machiavelli, Political Science, virtù.

\section{INTRODUÇÃO}

Maquiavelismo, substantivo masculino, e maquiavélico, adjetivo simples, são palavras hoje encontradas nos dicionários formais da língua portuguesa, assim como possuem seus equivalentes linguísticos nas mais diversas traduções às inúmeras línguas formais ao redor do globo. Estas palavras habitam tanto no universo político quanto no cotidiano popular, sendo proferidas com intenções pejorativas, como sinônimos da personificação da imoralidade, da falta de escrúpulos e do jogo sujo. Tais palavras têm sua origem em um dos clássicos da teoria política, Nicolau Maquiavel (SADEK, 2003).

De fato, os escritos de Maquiavel carregam consigo grande fama e, mesmo aos leigos em relação aos ensinamentos políticos de Maquiavel, seu

\footnotetext{
${ }^{1}$ Professor da UNIJUI - Universidade Regional do Noroeste do Estado do Rio Grande do Sul - Doutor em Administração/ UFP - Universidade Federal de Pernambuco - ariosto@unijui.edu.br (iD https://orcid.org/0000-0001-5212-4695

${ }^{2}$ Mestre em Sociologia Politica - UFSC - sparemberger@hotmail.com (iD) https://orcid.org/0000-0002-4345-5297
} 
nome é fundamentador de controvérsias. Porém, quem foi Nicolau Maquiavel? Quais ensinamentos políticos deixou? Se seu pensamento é realmente sórdido, por quais motivos este autor continua a ser estudado, lido e relido hodiernamente? A fim de responder estas perguntas, este artigo objetiva clarificar o pensamento político de Maquiavel, compreendendo seus principais ensinamentos e sua importância na ciência política.

Perante os objetivos propostos, esclarecemos que este estudo abordará de forma introdutória o pensamento de Maquiavel, compreendendo didaticamente questões centrais no pensamento do autor. Logo, focaremos nas interpretações dominantes do pensamento político de Maquiavel, evadindo debates controversos, resultantes das múltiplas interpretações das leituras provenientes dos escritos do filósofo italiano. Metodologicamente, este artigo, pelo método de revisão bibliográfica, pretende abordar o pensamento deste clássico da ciência política tanto por meio da leitura direta das principais obras políticas de Maquiavel (O Príncipe e Discursos sobre a primeira década de Tito Lívio), quanto à luz da interpretação de comentadores do pensamento maquiaveliano.

\section{MAQUIAVEL: HOMEM E OBRA}

Nascido em Florença, em maio de 1464, Niccolò di Bernardo Machiavelli cresceu em uma Itália fragmentada, desfigurada, dividida e dominada por forças estrangeiras (JUNIOR, 2007). Neste contexto, em que governos eram destituídos e a Itália não se encontrava unificada, Maquiavel ascende politicamente e ocupa a Segunda Chancelaria de Florença aos 29 anos, realizando missões diplomáticas tanto na Itália quanto na Europa. No ano de 1512, quando os Médicis retomam o poder de Florença, Maquiavel é deposto de seu cargo. No ano seguinte, acusado de ter participado de uma conspiração contra os Médicis, o fiorentino é preso e torturado (SKINNER, 2010).
Após o ocorrido, Maquiavel sai da prisão e enfrenta um exílio político em sua própria terra natal (SADEK, 2003). Neste momento, começa uma nova fase na vida do autor, momento no qual escreve suas grandes obras políticas, sendo elas: O Príncipe (1512-1513); Discursos sobre a primeira década de Tito Lívio (1513-1519) e A Arte da Guerra (1519-1520). Posteriormente ao seu isolamento, Maquiavel retorna a ocupar cargos na cidade de Florença, mas, desta vez, como historiador, sendo incumbido pelos Médicis da missão de escrever a história da cidade de Florença. Assim, publica seu último livro, denominado História de Florença, em $1525^{3}$ (FREITAS JUNIOR, 2007).

Entretanto a sorte não sorri para Maquiavel e após a queda de Roma, em maio de 1527, os Médicis são depostos e o conselho de Florença proclama a restauração da República. Em decorrência da ligação de Maquiavel com os Médicis, o fiorentino se vê impossibilitado de ocupar qualquer cargo público, uma vez que "a geração republicana não devia considerá-lo muito mais do que um protegido insignificante e envelhecido da tirania caída em descrédito" (SKINNER, 2010, p.117-118). Tal fato é cercado pela ironia histórica de que após tal infortúnio Maquiavel adoece, falecendo em 21 de junho de 1527 (SKINNER, 2010).

Quanto a sua formação, Nicolau Maquiavel desde a sua juventude teve contato com ideias republicanas e acesso as mais distintas obras clássicas disponíveis em sua época, por decorrência do fato de seu pai, advogado, ter apresentado em sua formação jurídica contato com ideias humanistas renascentistas. Consequentemente, o fiorentino frequentou aulas sobre autores latinos com professores de retórica. Maquiavel também era um grande conhecedor dos autores clássicos, como Tito Lívio, Cícero, Aristóteles e Lucrécio. Ademais, era notório seu conhecimento do latim, sendo que com apenas 12 anos o autor era capaz de redigir no melhor estilo da língua dos romanos (SKINNER, 2010).

\footnotetext{
${ }^{3}$ Além destas obras, Maquiavel escreveu a comédia A Mandrágora, A biografia de Castruccio Castracani e ensaios literários e poesias (FREITAS JUNIOR, 2007).
} 


\section{O MÉTODO DE MAQUIAVEL: A VER- DADE EFETIVA DAS COISAS}

De fato, Maquiavel positivou escritos que se perpetuam vivos ainda hoje, os quais influenciaram e influenciam pensadores das mais diversas gerações. Como ponto inicial para compreensão dos ensinamentos de Maquiavel, é imprescindível entendermos qual foi o método utilizado pelo autor na construção de seu conhecimento. Para isso, inicialmente apresentamos que Maquiavel, acima de tudo, foi um teórico do Estado. Em seus escritos, o fiorentino preocupou-se normativamente com as questões estatais, sendo que nestas preocupações, Maquiavel não buscou o melhor Estado possível, "aquele tantas vezes imaginado; mas que nunca existiu. Mas o Estado real, aquele capaz de impor a ordem" (SADEK, 2003, p. 17). Desta maneira, Maquiavel rompe com tradições idealistas na política ao pautar suas pesquisas pela verdade e pela realidade política.

Rompendo com a tradição Antiga e Medieval que imaginava um Estado ideal toda vez que se falava sobre o Estado, Maquiavel escreveu sobre o Estado real. Seguindo os métodos de interpretação histórica desenvolvidos por Políbio e outros historiadores antigos, Maquiavel interpreta a realidade das coisas e não busca imaginar reinos fictícios. Destarte, a história é, para Maquiavel, o verdadeiro livro da vida, no qual o homem, verificando e conhecendo o passado, deve tirar as lições necessárias para prever o futuro de cada Estado, bem como os sintomas e remédios eficazes, pois basta verificar sua eficácia, para as perturbações da ordem instalada (FREITAS JÚNIOR, 2007, p. 207).

Este método, pautado pela verdade e pelos fatos, foi conceituado por Maquiavel como a busca pela verità effettuale, ou, a verdade efetiva das coisas. "Esta é sua regra metodológica: ver e examinar a realidade tal como ela é e não como gostaria que ela fosse, a substituição do reino do deve ser [...] pelo reino do ser, da realidade" (SADEK, 2003 , p. 18). A verdade efetiva das coisas, como salienta Bignotto (2007), jamais deve ser compreendida como constatação de impotência humana em relação do dever ser, mas sim, ela se apresenta como um imperativo para ação humana na esfera política ou no mundo público. A inovação presente nos escritos de Maquiavel deve ser compreendida sob a égide do novo e do desbravamento de novas formas de pensar a política, como afirma Bignotto:

A obra de Maquiavel deve ser pensada sob o signo do novo - novidade tramada no convívio com o passado, construída pela leitura dos humanistas e tecida num confronto sinuoso com as crenças mais arraigadas dos séculos anteriores sobre a natureza da política e das ações dos homens (BIGNOTTO, 2007, p. XXV).

Nesta expedição metodológica, Maquiavel examina exemplos históricos dos reinos e principados, buscando exceções e regras a fim de construir seu pensamento sobre o Estado, o governo e a política. Tal método, quando empregado em seu livro, $O$ Príncipe, verifica exemplos da história acerca do comportamento do povo e do resultado das ações dos governantes, analisando e compreendendo as paixões humanas em relação às atitudes dos príncipes, tornando este livro uma espécie de manual de governo que um príncipe deve seguir para manter o poder e ampliar a grandeza de seu governo. Exemplificando tal afirmação e evidenciando sua operacionalização, citamos o Capítulo $\mathrm{XXVI}$ de $O$ Príncipe, denominado $O$ que convém a um príncipe para que este seja estimado, em que Maquiavel efetua uma análise histórica, a fim de aconselhar como um príncipe deve agir:

É muito útil também a um príncipe dar de si
exemplos raros acerca da governança interna,
similares àqueles que se narraram do Senhor
Bernabò de Milão; conta-se que, quando havia
ocasião em que qualquer um houvesse feito
algo extraordinário, ou no bem ou no mal, na
vida civil, ele encontrava um modo de premiá-
lo ou puni-lo, de forma que desse muito o que
falar depois. E, sobretudo, um príncipe deve,
em todas as suas ações, engenhar-se em dar
de si fama de grande homem e de excelente
cabeça (MAQUIAVEL, 2011, p.100).

Nos Discursos sobre a primeira década de Títo Lívio, Maquiavel examina a história de Roma, 
compreendendo os motivos de sua ascensão, glória e grandeza. Diferentemente de sua primeira obra política (O Príncipe) nos Discursos sobre a primeira década de Tito Lívio, Maquiavel não foca em observar exclusivamente os axiomas das ações dos príncipes, mas passa a se preocupar também com os valores e virtudes do povo e seu papel na construção da república. Nesta análise, o autor, ao investigar a história dos romanos, preocupa-se com valores e princípios que foram capazes de guiar Roma à grandeza, clarificando questões e ações políticas do passado, intencionando aconselhar ações política do presente. Nas palavras do autor:

Quem considere as coisas presentes e as antigas verá facilmente que são sempre os mesmos desejos e os humores em todas as cidades e todos os povos, e que eles sempre existiram. De tal modo que quem examinar com diligência as coisas passadas facilmente preverá as futuras, em qualquer república, prescrevendo os remédios que foram usados pelos antigos, pensará em novos, devido à semelhança dos acontecimentos (MAQUIAVEL, 2007, p. 121).

\section{VIRTÙ E FORTUNA: DOIS CONCEI- TOS ESSENCIAIS NA COMPREENSÃO DE MAQUIAVEL}

Como visto, os escritos políticos de Maquiavel se perpetuam pautados na verdade efetiva das coisas, ou seja, em uma análise realista da política. Nestes escritos, o autor, amparado em exemplos históricos, constrói seus preceitos teóricos acerca do Estado e da república, sendo que nestas construções, dois conceitos evoluem e ganham novos contornos na medida em que os escritos políticos de Maquiavel auferem forma, sendo eles essenciais para compreensão das ideias políticas do fiorentino. Estes conceitos são: virtù e fortuna.

De forma genérica, a virtù emerge em $\mathrm{O}$ Príncipe como um conjunto de qualidades necessárias que um príncipe deve possuir para manter e ampliar o seu poder, ao passo que a fortuna liga-se à contingência, aquilo que não se pode mudar, mas por algum motivo é daquela forma, podendo em determinados momentos ser considerada ben- ção ou infortúnio. Em Maquiavel, observa-se que os conceitos de virtù e fortuna estão conectados para conquista e para manutenção do poder, assim o governante virtuoso é aquele que sabe qual atitude tomar em qualquer situação, indiferentemente dos golpes da fortuna.

\begin{abstract}
Maquiavel utilizou o conceito de virtù para se referir a todo o conjunto de qualidades e possibilidades, sejam elas quais forem, cuja aquisição o príncipe possa achar necessária a fim de 'manter seu estado' e realizar grandes feitos. 0 motivo central do humanismo renascentista, talvez seja de que a virtù servia para vencer o poder da fortuna no controle dos negócios (ARNAUT; BERNARDO, 2002, p. 97).
\end{abstract}

Retratando a virtù e as questões mundanas, Maquiavel, no penúltimo capítulo de $O$ Príncipe, denominado Quanto pode a fortuna nas coisas humanas e de que modo resistir-lhe, estrategicamente aprecia a ideia "de que as coisas do mundo seriam governadas pela fortuna e por Deus, de modo que os homens, com a sua prudência, não poderiam corrigi-las" (MAQUIAVEL, 2011, p.111). Contudo, ao decorrer do capítulo, Maquiavel mostra -nos como, de certa forma, a fortuna pode ser controlada pela virtù, deixando a entender que a generosidade da fortuna sorri aos homens de virtù:

\begin{abstract}
Concluo que, variando a fortuna, e estando os homens obstinados em suas qualidades, são felizes enquanto ambas, fortuna e qualidades, concordam entre si e, quando discordam, infelizes. Eu bem penso isto: que seria melhor ser impetuoso do que cauteloso, porque a fortuna é mulher, e é necessário, querendo mantê-la submetida, contrastá-la e enfrentá-la. E se vê que ela se deixa mais facilmente vencer por estes do que aqueles que procedem friamente; e por isso sempre, como a mulher, a fortuna é amiga dos jovens, por que são menos cautelosos, mais ferozes e com mais audácia comandam (MAQUIAVEL, 2011, p.114).
\end{abstract}

Se em $O$ Príncipe a fortuna e a virtù aparecem ligadas às ações dos príncipes, de modo no qual os governantes detentores da virtù podem beneficiar-se da fortuna e até desafiá-la, no livro Discursos sobre a primeira década de Tito Lívio a 
virtù ganha novos contornos no pensamento político de Maquiavel. Na busca por compreender os motivos que carregaram Roma em direção à grandeza, Maquiavel percebe que não somente as ações dos governantes trilharam o caminho necessário para o sucesso, mas também a virtude do povo. Neste escrito, Maquiavel correlaciona, em seu pensamento republicano, a virtù ao povo, pois nesta obra de Maquiavel o povo apresenta-se como o defensor da liberdade. Nas palavras do autor:

\begin{abstract}
E sem dúvida, se considerarmos o objetivo dos nobres e o dos plebeus, veremos naqueles grande desejo de dominar e nestes somente o desejo de não ser dominados e, por conseguinte, maior vontade de viver livres, visto que podem ter menos esperança de usurpar a liberdade do que os grandes; de tal modo que, sendo os populares encarregados da guarda de uma liberdade, é razoável que tenham mais zelo e que, não podendo eles mesmos apoderar-se dela, não permitirão que outros se apoderem. (MAQUIAVEL, 2007, p. 24)
\end{abstract}

A virtù do povo, como elemento essencial para manutenção da liberdade, pode ser compreendida com maior ênfase no livro terceiro dos Discursos Sobre a Primeira Década de Títo Lívio, precisamente no item número trinta e um desta obra, denominado As repúblicas fortes e os homens excelentes mantêm em qualquer fortuna o mesmo ânimo e a mesma dignidade. Neste trecho de seu escrito, Maquiavel realiza uma comparação entre a virtù dos romanos em relação a dos venezianos. No exemplo trazido, nosso filósofo político ressalta a virtù dos romanos em preservar o ânimo na derrota e se abster da insolência após a vitória: "Quod romani, si vincuntur, non minuuntur animis; nec, si vincut, insolescere solent" (MAQUIAVEL, 2007, p. 415). Ao passo que o contrário ocorreu com os venezianos, os quais, pelas benevolências da fortuna, foram capazes de auferir vitorias, chegando a acre- ditar que possuíam a virtù que não tinham, contudo, ao degustarem a derrota, mostraram sua covardia, padecendo na falta de glória, fato que "levou-os a perder de uma só vez o Estado e a coragem" (MAQUIAVEL, 2007, p. 416). Após retratar comparativamente os romanos em relação aos venezianos, considerando a virtù e a fortuna, Maquiavel deixa claro a virtù do povo como um dos elementos essenciais para grandeza de uma nação. Nas palavras do autor:

\begin{abstract}
Portanto, se uma cidade for armada e ordenada como Roma, e se seus cidadãos, todos os dias, precisarem experimentar sua virtù e a força da fortuna, tanto na vida particular como na vida pública, estes, em quaisquer condições, terão o mesmo ânimo e manterão a mesma dignidade; mas, sempre que os cidadãos estiverem desarmados e se apoiarem somente nos ímpetos da fortuna, e não na própria virtù, seu ânimo variará com a variação daquela, e eles sempre darão o exemplo que foi dado pelos venezianos (MAQUIAVEL, 2007, p. 418).
\end{abstract}

Elucidamos que diversas interpretações sobre o papel do povo nos escritos de Maquiavel são possíveis. Neste artigo, expomos com maior ênfase a do povo como defensor e guardião da liberdade, contudo, existem controvérsias ${ }^{5}$ entre os comentadores do pensamento maquiaveliano acerca desta temática. Sobre esta controvérsia, alguns comentadores, como Skinner e seus seguidores, preferem atribuir um papel de passividade ao povo no pensamento político de Maquiavel, ao passo que outros comentadores, como John McCormick (2003), atribuem ao povo, no pensamento de Maquiavel, o papel de guardião da república e da liberdade republicana. Ademais, também existem interpretações agonísticas acerca desse tema, que realçam o papel do conflito entre o povo e os dominantes como um dos elementos do sucesso de Roma ${ }^{6}$.

\footnotetext{
4 “Porque os romanos, se são vencidos, não perdem o ânimo; e, se vencem, não costumam tornar-se insolentes” (MAQUIAVEL, 2007, p. 415).

${ }^{5}$ Para mais informações sobre estes debates ver: Silva (2010), Costa (2010) e Silva (2018).

${ }^{6}$ Acerca desta interpretação é imprescindível afirmarmos que os simpatizantes desta leitura de Maquiavel não afirmam que "todo conflito seja positivo para liberdade, mas apenas aqueles que são canalizados institucionalmente" (COSTA, 2010, p. 213), de modo que o "equilíbrio tenso é produzido por meio de um arranjo institucional que mobiliza um humor contra o outro, 'ambição contra ambição', e impede que um dos lados da cidade, ou um indivíduo cheguem à preponderância inconteste" (COSTA, 2010, p. 213).
} 


\section{4. ÉTICA E MORAL NO PENSAMENTO POLÍTICO DE MAQUIAVEL}

No escrito $O$ Príncipe, os preceitos estabelecidos sobre um bom governante e os paradigmas da moral convencional, constituem, em uma definição genérica, a relação de duas retas paralelas. Ao tratar sobre o dilema da virtù dos príncipes, Maquiavel coloca como um dos pré-requisitos para um bom governante adquirir o adjetivo de exercer o poder de não ser bom. Também neste escrito, Maquiavel afirma que a hipocrisia não é somente um valor fundamental para um príncipe, mas também que ela pode ser mantida durante quanto tempo for necessário para manutenção do poder. Além destes argumentos, o autor dirige-se contra a moralidade religiosa convencional ao sugerir que mesmo se as qualidades tidas como boas forem de fato virtudes, um governante que as despreze estaria caindo no vício, entretanto, se este vício for benéfico para a manutenção de seu governo e para sua imagem, ele não deve se preocupar, pois estará cumprindo sua obrigação fundamental que é a de manter o Estado. O rompimento de Maquiavel com a moralidade convencional pode ser observado ao longo de todo $O$ Príncipe.

Tais pontos presentes na obra de Maquiavel fazem com que uma leitura descontextualizada fomente a fama popular que o autor carregou ao longo da história, de modo que as palavras maquiavelismo e maquiavélico encontrem-se como sinônimos de imoralidade no cotidiano dos indivíduos. Portanto, ao compreendermos $O$ Príncipe, é necessário contextualizarmos os motivos que levaram Maquiavel a escrever tal obra no contexto vivenciado pelo autor.

Maquiavel, em vida, encontrou uma Itália fragmentada, dominada e saqueada por potências estrangeiras, sendo que os príncipes de sua época, ou deixavam-se dominar pelos prazeres dionisíacos ou seguiram rigidamente a moral cristã ${ }^{7}$, esquecendo-se do Estado e da manutenção do po- der. Tal fato, faz com que Maquiavel construa esperanças de uma Itália unificada e de um libertador para esta Itália, como fica claro em $O$ Príncipe:

Se bem tenha surgido, até aqui, certo vislumbre de esperança em relação a algum príncipe, parecendo poder ser julgado como dirigido por Deus para redenção da Itália, contudo foi visto depois como, no apogeu de suas ações, foi abandonado pela sorte. De modo que, tornada sem vida, espera ela por aquele que cure as suas feridas e ponha fim aos saques da Lombardia, às taxações no Reino de Nápoles e na Toscana, e a cure daquelas suas chagas já de há muito fistuladas. Vê-se como ela pede a Deus para que lhe mande qualquer um que a redima dessas crueldades e insolências bárbaras. Vê-se ainda ela toda pronta e disposta a seguir uma bandeira, desde que exista alguém que a levante (MAQUIAVEL, 2011, p. 116).

Quando Maquiavel redige $O$ Príncipe, ele o faz dirigindo-se à casa dos Médicis, governantes de Florença da época, com a intenção de que estes pudessem dominar as ingratidões da fortuna. Tal aspiração fica clara no último capítulo de O Príncipe, denominado Exortação à liberdade da Itália dominada pelos bárbaros, momento em que Maquiavel apela aos Médicis para que estes reconstruam e unifiquem a Itália:

\footnotetext{
Não se deve, portanto, deixar passar esta ocasião para que a Itália, depois de tanto tempo, finalmente tenha um redentor seu. Nem posso exprimir com que amor seria recebido em todas aquelas províncias que foram atingidas por essas inundações estrangeiras; e com que sede de vingança, com que obstinada fidelidade, com que piedade, com que lágrimas. Quais as portas que the seriam fechadas. Quais os povos que the negariam a obediência? Qual inveja que lhe seria imposta? Qual italiano lhe negaria a liberdade? A todos enoja esse domínio bárbaro. Encare, portanto, a vossa ilustre esse empreendimento com aquele ânimo e com aquela esperança que são próprias das causas justas, a fim de que, sob a sua insígnia, esta pátria seja nobilizada [...] (MAQUIAVEL, 2011, p.119).
}

\footnotetext{
${ }^{7}$ Maquiavel, ao pensar os valores cristãos, concluí que o cristianismo tem assombrosa culpa na corrupção dos governos, pois esta doutrina religiosa, ao reverenciar e exaltar princípios que pregam o desapego ao materialismo, a humildade e o altruísmo, teve como resultado tornar a humanidade fraca e oferecê-la como presa fácil aos maus feitores.
} 
Como visto, Maquiavel positivou seu pensamento em $O$ Príncipe direcionado para casa dos Médicis. Neste momento, o autor posicionava-se em favor de um governante capaz de retomar e unificar uma Itália fragmentada e calejada por invasões. Ao compor tal obra, Maquiavel pautou-se em redigir um escrito que fosse capaz de aconseIhar os governantes na manutenção do poder para assegurar a liberdade da nação, uma vez que o autor acreditava que, em dado momento, era preferível um governante capaz de manter o poder, mesmo que este precisasse se posicionar como déspota, em relação a governantes incapazes de manter a Itália livre.

Logicamente, $O$ Príncipe é um escrito controverso, pois, ao mesmo passo em que podemos compreendê-lo como um escrito de época, foi este escrito que fundamentou a contribuição mais significativa de Maquiavel à teoria política moderna. Neste livro, o teórico político fiorentino promoveu "a emancipação da esfera política das considerações morais e dos preceitos religiosos construídos ao longo de mais ou menos mil anos" (BEDIN, 2000, p.85).

Trata-se, indubitavelmente, como se percebe da 'proeminência da política', em substituição à tradicional 'proeminência da moral'. Nada de mais novo, de mais insólito, no crepúsculo da Idade Média, do que essa vontade de isolar a política de tudo o que ela não é, de tudo o que não constitui seu objeto próprio, isto é, a fundação, a conservação e ampliação do Estado, do que essa recusa em julgá-la em função dos valores morais estranhos a esse objeto, do que esse modo de examina-la com toda a liberdade de espírito e de tom, com toda sua lucidez, como o desapego do sábio e a frieza do técnico (CHEVALLIER, 1982, p. 275).

Mas, se $O$ Príncipe, a obra mais famosa de Maquiavel, pode ser entendida como um livro de época, como podemos compreender o pensamento político normativo de Maquiavel? A fim de responder tal pergunta, elucidamos os Discursos sobre a primeira década de Tito Lívio como o escrito em que Maquiavel perpetua o seu pensamento sobre a política de forma normativa. Neste escrito, o autor reestabelece alguns dos dilemas previa- mente presentes em $O$ Príncipe, colocando a liberdade e a pátria acima de qualquer valor ético e moral. Nas palavras do autor:

[...] porque, quando se delibera sobre a salvação da pátria, não se deve fazer consideração nenhuma sobre o que é justo ou injusto, piedoso ou cruel, louvável ou ignominioso; ao contrário, desprezando-se qualquer outra consideração, deve-se adotar plenamente a medida que the salve a vida e mantenha a liberdade (MAQUIAVEL, 2007, p. 443).

Por mais que os Discursos sobre a primeira década de Tito Lívio contenham elementos considerados imorais, outrora percebidos em $O$ Príncipe, é neste escrito que o autor fundamenta as bases de seu pensamento republicano, esclarecendo e dando voz aos valores republicanos, que para Maquiavel, possuem a capacidade de guiar uma nação em direção à liberdade e à grandeza, algo que Maquiavel sempre sonhou à sua amada cidade, Florença.

Nos capítulos finais do primeiro livro dos Discursos, Maquiavel apresenta os elementos que permitem esperar um futuro melhor para sua cidade natal. Se num Estado o povo e a elite dirigente estão corrompidos, não há nada a esperar a não ser a morte do corpo político. Se, ao contrário, o povo é saudável, é possível para um legislador tentar sua grande obra e criar uma república livre e potente. Talvez este tenha sido o sonho secreto do escritor. Confiante na qualidade do povo fiorentino e em seu amor pela liberdade, nunca deixou de esperar o retorno de uma república popular em sua pátria. Explicando o seu desejo e estabelecendo uma tipologia das formas corrompidas, no entanto, o secretário fiorentino não trai a inspiração inicial de sua reflexão política. Se faz questão de deixar a porta aberta para criação, é porque diz, claramente a seu leitor, mesmo um grande líder terá uma enorme dificuldade para construir instituições livres, se faltar ao povo a virtude necessária para mantê-las. Republicano convicto e apaixonado, Maquiavel nunca deixou de encarar suas esperanças através da lente saudável de seu realismo. (BIGNOTTO, 2007, p. XL) 
Os escritos de nosso cientista político, no que tangem a ética e a moral, não representam apenas a ruptura com os preceitos de seu tempo, mas sim, o surgimento de uma nova ética, na qual o Estado e a sua liberdade tornam-se os imperativos das ações humanas, ou seja, a ética como virtude cívica. Assim, a ética republicana de Maquiavel é a ética de um estado forte e livre. Em O Príncipe, Maquiavel estabelece que a política apresenta uma ética própria, e que desacreditá-la ou ignorá-la pode guiar uma nação à fraqueza e ao fracasso, ao passo que, nos Discursos sobre a primeira década de Tito Lívio, o autor vislumbra suas preferencias republicanas de forma normativa, alicerçando as bases de seus valores republicanos.

\section{CONSIDERAÇÕES FINAIS}

Como visto, o pensamento político de Maquiavel representou um marco na ciência política, fomentando o rompimento do idealismo em detrimento da verdade efetiva das coisas. O realismo político de Maquiavel, ao confrontar ensinamentos clássicos da política, evidenciou que a política demonstra a sua própria lógica e ética, contudo, a resistência dos indivíduos em aceitarem as dinâmicas do jogo político é o que causa repulsa e fomenta os significados negativos atribuídos aos escritos de Maquiavel. Apesar da conotação ultrajante atribuída a Maquiavel, seus escritos são objeto de estudo e guiam grande parte dos estudos políticos, sendo utilizados, ainda hoje, por defensores da liberdade.

Maquiavel, ao compreender as forças e as paixões políticas, buscou os adjetivos necessários aos governantes e ao povo para criação e manutenção de um Estado independente, livre de ameaças externas e capaz de garantir a liberdade de seu povo. Objetivando difundir suas ideias em uma Itália calamitosa, Maquiavel ofereceu ensinamento esotéricos nas entrelinhas de seus escritos, ou, como nos mostra Jaques Rousseau (apud SILVA, 2010, p.38), "Maquiavel, fingindo dar lições aos reis, deu-as ele, e grandes, aos povos". Portanto, é assim que devemos entender Maquiavel, um cidadão sem fortuna, mas, sobretudo, um intelectual de virtù (SADEK, 2003).

Em vida, Maquiavel contextualizou uma das grandes revoluções humanísticas, o renascimento. É neste contexto que podemos compreender a obra e os pensamentos do autor. Filho de sua época, Maquiavel presenciou um mundo em transformação, "um mundo redivivo, entre os séculos XIV e XVI, sucessor da letargia medieval e assentado em bases humanísticas e antropocêntricas" (BARROS, 2010, p. 17). É neste "ambiente intelectual renovado que vamos encontrar nosso pensador, que assim como Leonardo e Michelangelo, deve ser visto como uma das máximas encarnações do espírito renascentista" (BARROS, 2010, p. 18), de modo que, "como orgulhosamente nos lembra a inscrição na lápide de Maquiavel, 'nenhum epitáfio pode fazer jus a tão grande nome'" (SKINNER, 2010, p. 119).

\section{REFERÊNCIAS}

ARNAUT, Cezar. BERNARDO, Leandro Ferreira. Virtù e Fortura no pensamento político de Maquiavel. Acta Scientiarum, Maringá, v. 24, n. 1, p. 91102,2002

BARROS, Vinícius Soares de Campos. 10 Lições sobre Maquiavel. Petrópolis: Vozes, 2010.

BEDIN, Gilmar Antônio. O Realismo Político e as Relações Internacionais: algumas reflexões sobre o paradigma tradicional das relações internacionais. In: BEDIN, Gilmar Antônio. OLIVEIRA, Odete Maria de. SANTOS JUNIOR, Raimundo B. dos. MIYAMOTO, Shiquenoli. Paradigmas das Relações Internacionais. Ijuí: Editora UNIJUI, 2000.

BIGNOTOO, Newton. Introdução aos Discursos sobre a primeira década de Tito Lívio de Nicolau Maquiavel. In: MAQUIAVEL, Nicolau. Discursos sobre a primeira década de Tito Lívio. São Paulo: Martins Fontes, 2007.

CHEVALLIER, Jean-Jacques. História do pensamento político. Tomo I. Trad. De Roberto Cortes da Lacerda. Rio de Janeiro: Guanabara, 1982. 
COSTA, Jean Gabriel Castro da. Maquiavel e o trágico. 2010. Tese (Doutorado em Ciência Política) - Faculdade de Filosofia, Letras e Ciências Humanas, Universidade de São Paulo, São Paulo, 2010. doi: 10.11606/T.8.2010.tde-09022011125526. Acesso em: 7 jun. 2020.

FREITAS JÚNIOR, Antonio de. O pensamento político de Maquiavel. 2007. Disponível em: https:// www12.senado.leg.br/ril/edicoes/44/174/ ril_v44_n174_p205.pdf. Acesso em: 6 jun. 2020.

MAQUIAVEL, Nicolau. Discursos sobre a primeira década de Tito Lívio. São Paulo: Martins Fontes, 2007.

MAQUIAVEL, Nicolau. O Príncipe. Petrópolis: Vozes, 2011.

MCCORMICK, John P. “Machiavelli against republi- canism on Cambridge School's 'Guicciardinan Moments'”. Political Theory, 31 (5): 615- 643. 2003.

SADEK, Maria Tereza. Nicolau Maquiavel: o cidadão sem fortuna, o intelectual de virtù. In: WEFFORT, Francisco C. (org.). Os Clássicos da Política 1. 13. ed. São Paulo: Ática, 2003.

SKINNER, Quentin. MAQUIAVEL. Porto Alegre: L\&PM, 2010.

SILVA, Ricardo. Maquiavel e o conceito de liberdade em três vertentes do novo republicanismo. RBCS Vol. $25 n^{\circ} 72$ fev. p.37-58, 2010.

SILVA, Ricardo. A República democrática de Maquiavel: uma crítica à interpretação antiinstitucionalista. Rev. bras. Ci. Soc. São Paulo, v. 33, n. 98, 2018. 